\title{
Using Inquiry Teaching to Promote Student Critical Thinking and Content Knowledge in a Nonmajors Biology Course
}

\author{
Miao Gao ${ }^{1,}$, , Ian J. Quitadamo² \\ ${ }^{1}$ Department of Early Childhood Education, School of Education, Nanjing Normal University, Nanjing, China \\ ${ }^{2}$ Departments of Biological Sciences and Science Education, Central Washington University, Ellensburg, WA, United States of America
}

Email address:

miaomiao789789@gmail.com (Miao Gao),iq@cwu.edu (Ian J. Quitadamo)

To cite this article:

Miao Gao, Ian J. Quitadamo. Using Inquiry Teaching to Promote Student Critical Thinking and Content Knowledge in a Nonmajors Biology Course. Education Journal. Vol. 4, No. 4, 2015, pp. 182-188. doi: 10.11648/j.edu.20150404.17

\begin{abstract}
A national focus on inquiry teaching promotes critical thinking and content knowledge; however, few studies show the level of inquiry needed to develop both outcomes. This study compared the effects of full inquiry $(n=21)$ or partial inquiry $(n=24)$ on undergraduate nonmajors biology critical thinking and content knowledge gains. Pre- and posttest assessment using the Critical thinking Assessment Test and three common content exams showed both full and partial inquiry improved students' critical thinking ability, but only full inquiry significantly increased content knowledge.
\end{abstract}

Keywords: Inquiry Teaching, Critical Thinking, Content Knowledge, Quantitative, Assessment

\section{Introduction}

International and domestic competitiveness of United States undergraduates is largely dependent on their ability to problem solve and critically think. An increasing number of national reports indicate a growing concern about the effectiveness of higher education teaching practices and decreased science and mathematics performance of U.S. students relative to other countries (National Academy of Sciences, National Academy of Engineering, and Institute of Medicine 2005; National Science Board 2007; The Task Force on the Future of American Innovation 2005; U.S. Department of Education 2000). While a majority of college faculty deem critical thinking to be an essential skill, only a small fraction of students can actually demonstrate this skill using a standardized instrument (Association of American Colleges and Universities 2005). This shows an apparent discrepancy between faculty expectations and students' ability to think critically.

Critical thinking (CT) can be defined as a process of purposeful self-regulatory judgment that drives problem solving and decision making (Facione 2011). At the core of CT are the component skills of analysis, interpretation, inference, explanation, evaluation, and self-regulation (Facione 2011; Facione 1990). Critical thinking skills are key to student academic, professional and personal success because increased CT skill is associated with higher cumulative grade point average (GPA), competing positively in the job market, making rational decisions in one's personal life, and engaging in important issues as an informed citizen (Association of American Colleges and Universities 2005).

The role of CT in increasing content knowledge has often been misunderstood. Although conceived of as separate constructs, content knowledge and CT are interrelated. When $\mathrm{CT}$ is considered as a process, content knowledge simply becomes the raw material that is mentally processed (Bailin 2002). In other words, you cannot think critically about nothing. Critical thinking, particularly subcomponent skills of analysis, evaluation, and inference, are necessary to build a deeper understanding of scientific knowledge, to make content knowledge meaningful to students, and to apply content knowledge to real life issues. The National Research Council (2000) recommends that science be taught via inquiry, simulating authentic scientific investigation or, simply stated, the process of 'doing science' (Nadelson 2009). Recently, greater focus has been placed on students developing a 'sense of place' during inquiry; thus making the material relevant, and therefore, more meaningful. Students who design and conduct investigations in response to real life issues, grapple with bringing structure to ill-defined problems, choose suitable methods, collect and analyze data, and draw conclusions, may more effectively develop CT (Fencl 2010; 
Author et al. 2008). Case studies, particularly those that use real life scenarios, also help students develop CT skills as they acquire new content knowledge (Chaplin 2009; Noblitt, Vance, and Smith 2010).

Although inquiry is accepted as the preferred method for teaching science by many researchers and practitioners, learning how to implement inquiry to foster CT and content knowledge in science is less evident. The majority of instructors held limited views of inquiry-based science teaching (Capps and Crawford, 2013). The open-ended nature of authentic scientific inquiry is a challenge for teachers in inquiry-based classrooms (Etheredge and Rudnistsky 2003), especially when adding the complexity associated with improving thinking along with content outcomes. The efficacy of inquiry-based teaching has been continually challenged (Furtak, Seidel, Iverson and Briggs, 2012), and the evaluation of inquiry-based teaching has been somewhat lacking. While a number of studies have generally shown positive effects of inquiry teaching (Anderson 2002; Timmerman, Strickland, and Carstensen 2008), very few studies have investigated whether inquiry affects CT and content knowledge gains simultaneously (Burris and Garton 2007). Much of the work that has been done is qualitative, and in many cases does not provide convincing evidence for skeptics who require quantitative results.

Previous quantitative research (Author et al. 2008) showed one form of inquiry teaching significantly improved student CT skills compared to traditional teaching. We wondered whether full inquiry teaching was necessary to improve student $\mathrm{CT}$ and content knowledge, or does partial inquiry work as well? Based on previous findings, the research questions for this study were:

Q1: What level of inquiry is necessary to improve CT and content knowledge in an undergraduate nonmajors biology course?

Q2: Within an inquiry teaching framework, what relationships exist between $\mathrm{CT}$ and content knowledge performance?

\section{Methods}

\subsection{Participants}

Participants were chosen from a nonmajors introductory biology course in fall 2009 at a regional comprehensive public university in the Pacific Northwest. Participants included forty five undergraduate students. Students were informed about the research and gave human subject consent on the first day of the class. Students were randomly grouped into two laboratory sections. Each lab implemented a different teaching method: full inquiry $(n=21)$ or partial inquiry $(\mathrm{n}=24)$. The same instructor taught both sections. The graduate students taught either the full or the partial inquiry section in the laboratory. Participant demographics (see Table 1) were gathered through a survey, with a response rate of $84 \%$.

Table 1. Participant demographics.

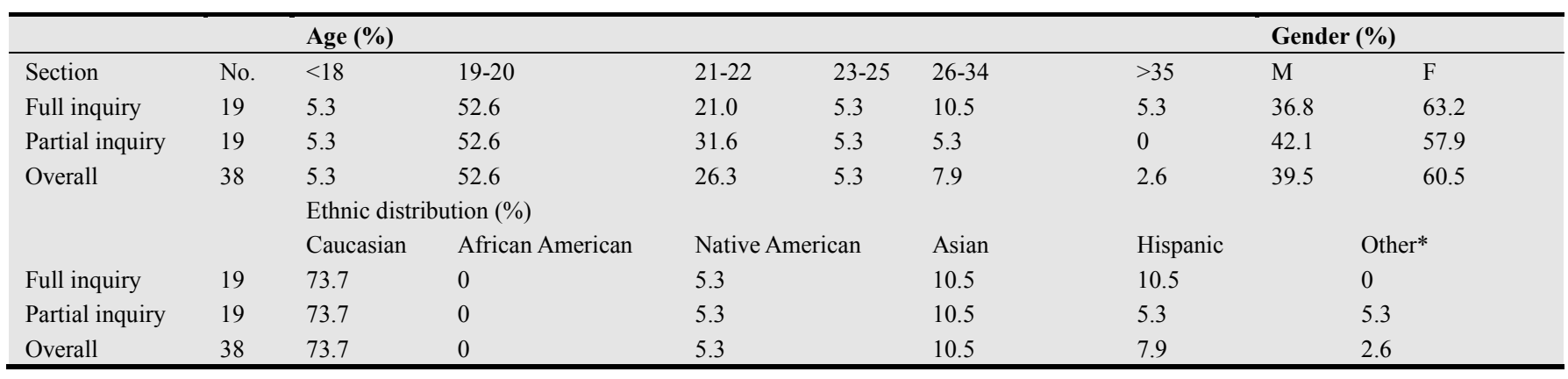

*Other includes "Choose not to answer" response.

\subsection{Instruction}

All participants received identical discipline-based content, used the same textbook, and were exposed to the same classroom environment during the 10 -week term. All students participated in case study exercises during scheduled lectures.

The full inquiry section implemented an immersive quarter-long group research project based on student-driven questions. The intent was to emulate the process that professional scientists use to investigate natural phenomena (NRC 2000). Each group of four students was taken into the field to make observations on the first day of laboratory. This was done to stimulate thought-provoking research questions. Each group collaboratively discussed their research questions and chose one to research for the duration of the quarter. Examples of research topics included a comparison of water quality between two local ponds, analysis of crayfish eating behavior, and a survey of bacteria on water fountains. Each group collaboratively wrote an initial and final research proposal, including literature-supported background, research question, null and alternative hypotheses, prediction(s), and experimental design. Proposals were submitted through the on-campus Blackboard system. Instructors and teaching assistants electronically edited and inserted comments and questions. Students revised their work and submitted a final proposal prior to beginning their research project. Each group then worked with the instructor and teaching assistants to carry out their experiment. Once data was collected, the instructor and teaching assistants used a just-in-time approach and Socratic questions to guide student analysis of raw data using basic statistics and graphing in Excel. A lab 
notebook was used to record all research activities and results as the project progressed. Each group of students orally defended their research at a public poster session during the final week of the laboratory.

The partial inquiry section used conventional prescriptive laboratory exercises for the first half of the quarter, including use of microscopes, prokaryotic and eukaryotic cells, principles of heredity, genetic problem solving and evaluating the 5 -second rule. In the second half of the term, students transitioned to a more guided group research project. Like the full inquiry section, small group work was used, but research topic areas were themed and constrained by the instructor (e.g. comparing different surfaces or products for the presence of bacteria). An initial proposal, final proposal, experiment, basic data analysis, and assessments were used as in the full inquiry section; however, the partial inquiry section presented their research project orally using Microsoft PowerPoint. A comparison of course components in the full and partial inquiry sections is shown in Table 2.

Table 2. Course components used in full and partial inquiry sections.

\begin{tabular}{lll}
\hline Course component & Full inquiry & Partial inquiry \\
\hline Lecture & + & + \\
Case studies & + & + \\
Conventional laboratories & + & +++ \\
Group research projects & 9 weeks & 4 weeks \\
Small group discussion & +++ & + \\
Proposal & + & + \\
Presentation & Poster & Oral with PowerPoint \\
Collaborative writing & +++ & + \\
Rubric & + & + \\
Peer evaluation & + & + \\
\hline
\end{tabular}

Note: + and +++ indicate relative use of the course component.

\subsection{Assessment}

CT performance was measured using the Critical thinking Assessment Test (CAT). Pre- and posttests were given to students in both full and partial inquiry sections at the beginning and end of the quarter. Students were aware that taking the CAT test was voluntary and would not affect their course grade. The CAT was chosen to measure CT because it is a reliable NSF-supported instrument that assesses four areas of CT: evaluation and interpretation, problem solving, creative thinking, and effective communication (Stein 2006). Each question contains one or more components related to $\mathrm{CT}$. Most questions in the CAT instrument require short answer responses derived from provided information. A group of faculty, graduate, and undergraduate students facilitated by a nationally trained facilitator was assembled to score each test. A published rubric provided by the test manufacturer was used to score a representative sample in order to calibrate scorers relative to each other. Each response was evaluated by two scorers. If the two scores did not agree, that question was evaluated by a third scorer. After each question was scored, tests were collected by the facilitator and randomly redistributed for scoring the next question.

Course performance was assessed using a combination of traditional content exams and quizzes, as well as case studies, group research projects, group presentations, and peer evaluation (see Table 3 ).

Table 3. Course components used to assess learning performance.

\begin{tabular}{lll}
\hline Assessment component & Points & Percentage of total course \\
\hline Exam & 300 & 47 \\
Quizzes & 50 & 8 \\
Case study & 50 & 8 \\
Research proposal & 50 & 8 \\
Research presentation & 100 & 15 \\
Peer evaluation & 30 & 5 \\
Lab notebook/lab handout* & 50 & 8 \\
Biology in the news & 10 & 1 \\
\hline
\end{tabular}

* Lab notebook applied to full inquiry; lab handout applied to partial inquiry.

Three exams were used to assess content knowledge performance. The content themes of three exams were cells (exam 1), genetics/inheritance (exam 2), and evolution and diversity (exam 3). All exams contained 45-50 multiple choice questions administered and scored online using the Blackboard course management system. Each multiplechoice question was categorized using Bloom's taxonomy (Anderson and Krathwohl 2001; Lord and Baviskar 2007). The proportion of each question type across all three exams was $40 \%-50 \%$ knowledge, $20 \%-50 \%$ comprehension, $2 \%-$ $10 \%$ application, and 10\%-30\% analysis. Group research project proposals and presentations were assessed using rubrics. Whereas a common rubric was used for research proposals for two sections, slightly different rubrics were used for research presentations, since the full inquiry section presented in a poster session and partial inquiry presented orally.

A survey that assessed all students' background experiences with science was given to both sections at the end of the quarter. The survey responses of each student were coded for further data analysis.

\subsection{Statistical Analysis}

A repeated measures analysis of variance (RM ANOVA) was used to analyze pre- and posttest CT gains between and within full and partial inquiry sections. Content performance was also analyzed across all three exams using a RM ANOVA. Analysis of covariance (ANCOVA) was used to compare average exam performance between sections using age, gender, class standing, ethnicity and CT average performance as covariables. Pearson correlation was used to determine associations between CT gains and content exam performance.

\section{Results}

One of the main goals of this study was to investigate what level of inquiry in science teaching is necessary to measurably improve student CT. Results revealed that 
students who experience either full inquiry or partial inquiry teaching gained CT skill, with $3.20 \%$ and $2.84 \%$ gains, respectively (see Figure 1). Repeated measures ANOVA showed no significant differences in pre- and posttest CT performance between full and partial inquiry sections.

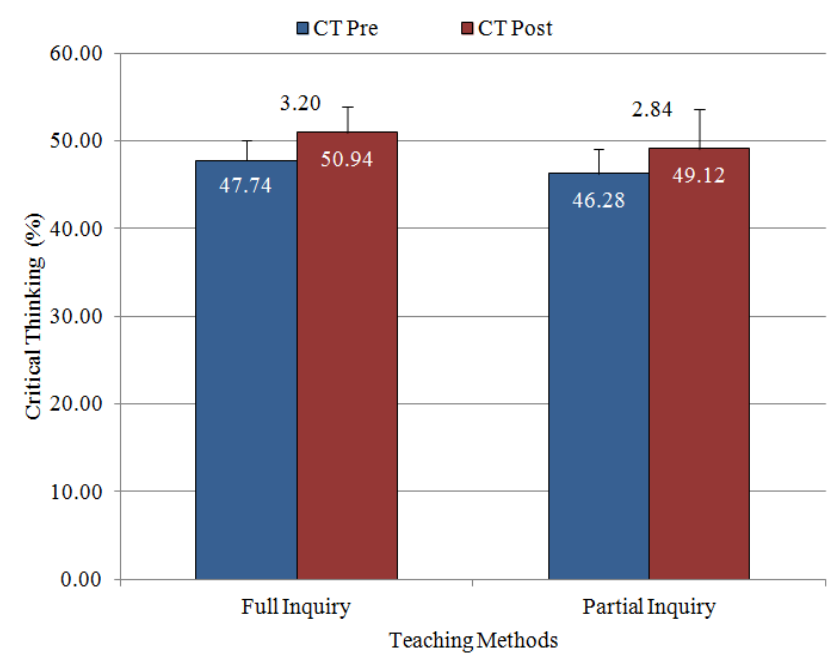

Figure 1. Total critical thinking performance.

A post hoc analysis of the component skills of CT showed meaningful differences between the two teaching methods. Full inquiry showed greater gains in creative thinking and effective communication ( $4.20 \%$ and $4.76 \%$ respectively); whereas partial inquiry showed greater gains in evaluation and interpretation, and problem solving with $4.71 \%$ and $2.94 \%$, respectively (see Figure 2). No significant gains were found in these four component skills.

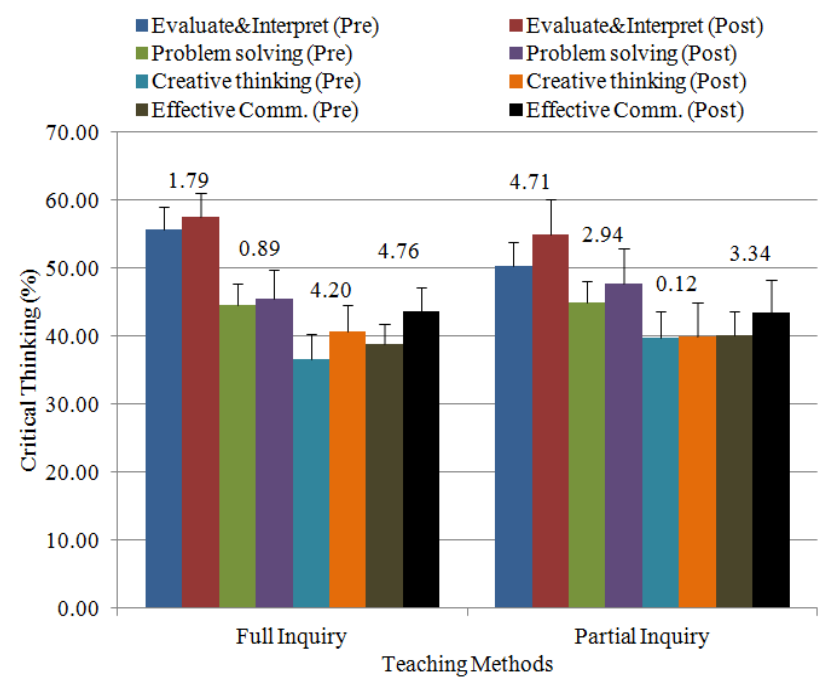

Figure 2. Component critical thinking performance.

Another goal of this research study was to investigate how the level of inquiry teaching impacted student content knowledge performance. The RM ANOVA showed that student content exam performance differed significantly between full and partial inquiry sections $(p=0.049, n=40)$. Figure 3 shows the average percentage score for content exams from full and partial inquiry sections.

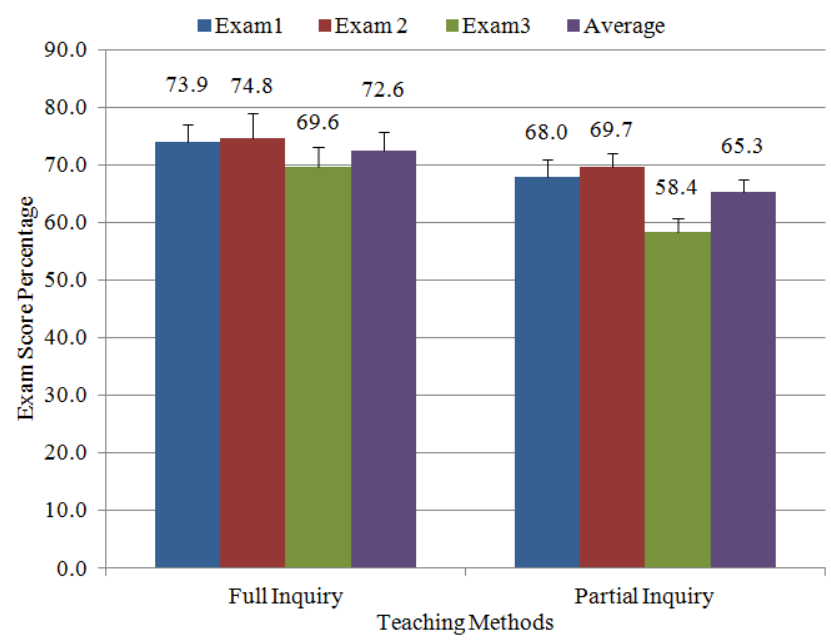

Figure 3. Content exam performance for full and partial inquiry sections.

An ANCOVA analysis indicated that average content exam performance differed significantly between sections when age, gender, class standing, ethnicity, and average CT performance $(p=0.031, n=30)$ were considered as covariables. None of the covariables differed significantly between sections. A sample size of 30 was used due to the need to match three completed exams with completed survey results. No other variables were found to significantly affect content exam performance between full and partial inquiry sections (see Table 4).

Table 4. ANCOVA analysis of full and partial inquiry sections on content exam performance.

\begin{tabular}{lllll}
\hline & F & Sig. & Observed Power & Effect size \\
\hline Section & 5.255 & $0.031^{*}$ & 0.593 & 0.186 \\
Age & 2.459 & 0.131 & 0.324 & 0.097 \\
Gender & 0.003 & 0.955 & 0.050 & 0.000 \\
Class standing & 0.035 & 0.854 & 0.054 & 0.002 \\
Ethnicity & 0.447 & 0.511 & 0.098 & 0.019 \\
CT average & 3.054 & 0.094 & 0.388 & 0.117 \\
\hline
\end{tabular}

* Significant at $\mathrm{p}=0.05$ level.

The relationship between $\mathrm{CT}$ gains and content exam performance was significant, particularly for exam 3 ( $p=$ $0.041, n=30$ ). In addition, RM ANOVA showed that student performance on exam questions differed significantly ( $p<$ $0.01, n=40$ ) among Bloom's cognitive levels. Full inquiry students showed greater scores on all question types as compared to partial inquiry (see Table 5).

Table 5. Correct answer percentage on content exams.

\begin{tabular}{llllll}
\hline & Exam 1 (\%) & & Exam 2 (\%) & & Exam 3 (\%) \\
\hline Cognitive level* & Full inquiry & Partial inquiry & Full inquiry & Partial inquiry & Full inquiry \\
\hline Knowledge & 60 & 55 & 58 & 52 & 73 \\
\hline
\end{tabular}




\begin{tabular}{lllllll}
\hline & Exam 1 (\%) & Exam 2 (\%) & & \multicolumn{2}{c}{ Exam 3 (\%) } \\
\hline Comprehension & 67 & 63 & 66 & 64 & 65 & 54 \\
Application & 77 & 77 & 67 & 52 & 74 & 65 \\
Analysis & 47 & 39 & 43 & 34 & 61 & 52 \\
\hline
\end{tabular}

*Cognitive level demonstrated on exams based on levels of Bloom's Taxonomy.

\section{Discussion and Future Directions}

The intent of this study was to investigate how the extent of inquiry affects CT, and how content knowledge might be associated with CT. Results showed that, while full inquiry had slightly greater gains than partial inquiry, both teaching methods produced overall gains in total CT performance. This result could be explained by the inclusion of case studies and group research projects in both sections. Case studies have been shown to be an effective component of inquiry teaching in fostering student CT skills (Noblitt, Vance, and Smith 2010; Author et al. 2008; Walton 2008). Case studies serve to connect student experiences to textbook content, making them more relevant to student daily life. This increases student engagement and reinforces scientific principles and thought processes valued by the scientific community, including CT (Author et al. 2008).

It is interesting to note that the level of inquiry affects component CT skill gains differently. Students in the full inquiry section showed greater increases in the component skills of creative thinking and effective communication. In contrast, the partial inquiry section demonstrated greater gains in component skills of evaluation and interpretation, as well as problem solving. This difference is not fully understood; however, it is possible the greater emphasis on writing in the full inquiry section was influential. Previous studies indicate that writing has a significantly positive effect on analysis, inference and evaluation (Facione 1990; Author and Author 2007), skills that overlap considerably with the component skills from the CAT test. Another study also showed that full writing assignments showed a significant benefit over short answer essay approach (Franklin, Weinberg and Reifler, 2014). In this study, student-generated research questions and the immersive collaborative writing used in the full inquiry section may have resulted in improved creative thinking and effective communication skills. It is unlikely that any one element caused the CT gains; rather, the combination of multiple elements probably produced observed gains in CT.

Repeated measures ANOVA results indicated that content exam performance differed significantly between full and partial inquiry sections. Interestingly, the full inquiry section performed much better on the final content exam. Although not conclusive, these results indicate that level of inquiry teaching may relate to content performance, such that students experiencing full inquiry may perform more strongly in content over the long term. Further, average CT performance was significantly related to exam three but not exams one and two. Thus, improving CT skills may have the potential to foster greater learning gains in content knowledge over time as well.

The previous interpretation is further supported by an analysis of exam content in relation to content covered by student research projects. It is unclear how each group's research project might have impacted student content performance. Each of the full and partial inquiry sections included six groups. Full inquiry projects focused on topics such as water quality, crayfish feeding behavior, and bacterial diversity. All groups in the partial inquiry section focused on projects related to bacteria. These topics were not formally or explicitly assessed on content exams. Considering the topics for the three content exams were cell, genetics/inheritance, and evolution and diversity, there is no obvious connection between research project and content exam topics that might have predisposed the full or partial inquiry students to have better content performance.

Correct answer percentage differed significantly between knowledge, comprehension, application, and analysis question types across all three content exams. While the data for the RM ANOVA and ANCOVA tests comparing full and partial inquiry met statistical assumptions, the data for the RM ANOVA comparing question types did not due to a significant Levene's test of error distribution $(p<0.05)$ across groups. As a result, care should be taken not to draw major conclusions on question type. Levene's violations and limited item type prevented their use in this analysis; however, the measured differences make them a worthwhile focus for future study.

This study showed that CT gains are possible using inquiry based laboratories; however, instructor ability to intentionally weave $\mathrm{CT}$ and scientific inquiry together within a nonmajors course framework is also likely to affect CT gains. Previous research indicates that larger $\mathrm{CT}$ gains may require this level of integration (Author et al. 2008). Furthermore, the use of more intensive writing in the full inquiry section may have predisposed those students to larger total CT gains as well as differentially affecting component CT skills development (Author and Author 2007). This study revealed that component CT skills were affected differently with full and partial inquiry. Discerning how these and other instructional elements affect CT skills, either individually or collectively, will require further research.

This study attempted to quantitatively evaluate the effects of level of inquiry teaching on CT and content knowledge performance. An acceptable number of participants were recruited for this study; however, including a larger number of participants would improve the study's validity. The three content exams used to evaluate content knowledge were not standardized biology exams, and it is possible that this affected the distribution of question type across the three content exams. Future studies should consider using a 
standardized biology content exam to more validly and reliably measure pre- and posttest content knowledge performance.

\section{Conclusion}

Based on previous research literature and results from the current study, we conclude that full inquiry and partial inquiry teaching improve student CT ability overall, but differentially affect component CT skills. As a research-based instructional method that more accurately represents authentic scientific investigation, full inquiry has the potential to improve creative thinking, effective communication, and content knowledge to a greater extent than partial inquiry. The results of this study are encouraging for faculty who seek alternatives to traditional teaching pedagogies if their goal is to improve student CT and content knowledge. As the search for better ways to teach and learn science moves forward, full inquiry should be considered as an effective science instructional method.

\section{Acknowledgements}

Thanks the great help from Central Washington University. We also acknowledge Nanjing Normal University for all the support and Jiangsu Province Brand Major Construction funded project.

\section{References}

[1] Anderson, Ronald D. 2002. Reforming Science Teaching: What Research Says About Inquiry. Journal of Science Teacher Education 13 (1):1-12.

[2] Association of American Colleges and Universities. 2005. Liberal Education Outcomes: A Preliminary Report on Student Achievement in College. Washington, D.C.

[3] Bailin, Sharon. 2002. Critical Thinking and Science Education. Science and Education 11 (4):361-75.

[4] Burris, Scott, and Bryan L. Garton. 2007. Effect of Instructional Strategy on Critical Thinking and Content Knowledge: Using Problem-Based Learning in the Secondary Classroom. Journal of Agricultural Education 48 (1):106-116.

[5] Capps, D. K., and Crawford, B. A. 2013. Inquiry-based instruction and teaching about nature of science: Are they happening? Journal of Science Teacher Education 24(3): 497526 .

[6] Chaplin, Susan. 2009. Assessment of the Impact of Case Studies on Student Learning Gains in an Introductory Biology Course. Journal of College Science Teaching 39 (1):72-79.

[7] DebBurman, Shubhik K. 2002. Learning How Scientists Work: Experiential Research Projects to Promote Cell Biology Learning and Scientific Process Skills. Cell Biology Education-Life Science Education 1 (4):154-172.

[8] Etheredge, S., and A. Rudnistsky. 2003. Introducing Students to Scientific Inquiry: How Do We Know What We Know? Boston, MA: Allyn and Bacon.
[9] Facione, Peter. 2011. THINK Critically. Upper Saddle River, NJ: Prentice Hall.

[10] Facione, Peter A. 1990. Critical Thinking: A Statement of Expert Consensus for Purposes of Educational Assessment and Instruction. Research Findings and Recommendations.

[11] Fencl, Heidi S. 2010. Development of Students' CriticalReasoning Skills through Content-Focused Activities in a General Education Course. Journal of College Science Teaching 39 (5):56-62.

[12] Franklin, D., Weinberg, J., \& Reifler, J. 2014. Teaching Writing and Critical Thinking in Large Political Science Classes. Journal of Political Science Education 10(2): 155165 .

[13] Furtak, E. M., Seidel, T., Iverson, H., and Briggs, D. C. 2012. Experimental and Quasi-Experimental Studies of InquiryBased Science Teaching A Meta-Analysis. Review of Educational Research 82(3): 300-329.

[14] Nadelson, L. S. 2009. How Can True Inquiry Happen in K-16 Science Education? Science Educator 18 (1):48-57.

[15] National Academy of Sciences, National Academy of Engineering, and Institute of Medicine. 2005. Rising Above The Gathering Storm: Energizing and Employing America for a Brighter Economic Future. Washington, D.C.: Committee on Prospering in the Global Economy of the 21st Century.

[16] National Research Council. 2000. How People Learn: Brain, Mind, Experience, and School. Expanded Edition. Edited by J. D. Bransford, A. L. Brown and R. R. Cocking. Washington, D.C.: National Academy Press.

[17] National Science Board. 2007. A National Action Plan for Addressing the Critical Needs of the U.S. Science, Technology, Engineering, and Mathematics Education System. Washington, D.C.: National Science Foundation.

[18] Noblitt, Lynnette, Diane E. Vance, and Michelle L. DePoy Smith. 2010. A Comparison of Case Study and Traditional Teaching Methods for Improvement of Oral Communication and Critical-Thinking Skills. Journal of College Science Teaching 39 (5):26-32.

[19] Quitadamo, Ian J., Celia L. Faiola, James E. Johnson, and Martha J. Kurtz. 2008. Community-Based Inquiry Improves Critical Thinking in General Education Biology. CBE - Life Sciences Education 7 (3):327-337.

[20] Quitadamo, Ian J., and Martha J. Kurtz. 2007. Learning to Improve: Using Writing to Increase Critical Thinking Performance in General Education Biology. CBE - Life Sciences Education 6 (2):140-154.

[21] Schwartz, Marc S., Philip M. Sadler, Gerhard Sonnert, and Robert H. Tai. 2009. Depth versus Breadth: How Content Coverage in High School Science Courses Relates to Later Success in College Science Coursework. Science Education 93 (5):798-826

[22] The Task Force on the Future of American Innovation. 2005. The Knowledge Economy: Is the United State Losing Its Competitive Edge?

[23] Timmerman, B.E., D.C. Strickland, and S.M. Carstensen. 2008. Curricular Reform and Inquiry Teaching in Biology: Where are our Efforts Most Fruitfully Invested? Integrative and Comparative Biology 48 (2):226-240. 
[24] U.S. Department of Education. 2000. Before It's Too Late: A Report to the Nation from the National Commission on Mathematics and Science Teaching for the 21st Century. Washington, D.C.: U.S. Department of Education.
[25] Walton, K.L.W. 2008. Use of Case Studies and Data Analysis to Improve Critical Thinking Skills in a One-semester Anatomy and Physiology Course. FASEB Journal 22:767.6. 